\title{
A questão curricular na autoavaliação da instituição de educação superior
}

\author{
MARIA ANGÉLICA RODRIGUES MARTINS*
}

\section{RESUMO}

O trabalho realiza exercício de análise, referenciado pelo atual quadro da educação superior brasileira e pelas condiçóes em que a docência é exercida em grande parte das instituiçóes. No texto, entrelaçam-se contextos, objetivos e condiçóes institucionais e teoria curricular que permeiam ou podem permear práticas avaliativas interessadas em contribuir para o desenvolvimento profissional de docentes da educação superior. O estudo focaliza o currículo na autoavaliação da instituição de educação superior (IES), no momento em que se toma o curso como unidade de análise. Dedica especial atenção às questôes relacionadas por Gimeno Sacristán (2000), quanto à objetivaçáo do currículo, entendido como confluência de práticas. Seu objetivo consiste em discutir a possibilidade e conveniência da inclusão de itens que remetem a essas questóes em procedimentos e instrumentos de autoavaliação de cursos pelo corpo docente.

Palavras-chave: ensino superior, currículos, professores, avaliação.

\section{RESUMEN}

El trabajo realiza un análisis que toma como referencia el actual panorama de la educación superior brasileńa y las condiciones bajo las cuales se ejerce la docencia en gran parte de las instituciones. En el texto se entrelazan contextos, objetivos, condiciones institucionales y la teoría curricular, que permean o pueden permear las prácticas de evaluación que puedan

* Professora do Programa de Pós-graduação em Educação e Coordenadora do Programa de Avaliação Institucional (PROAI) da Universidade Católica de Santos (Unisantos) (m-angelica@unisantos.br) 
contribuir al desarrollo profesional de los profesores de educación superior. El enfoque del presente estudio es el currículo en la autoevaluación de la Institución de Educación Superior (IES) en el momento en que se toma el curso como unidad de análisis. Se dedica especial atención a las cuestiones destacadas por Gimeno Sacristán (2000), en lo concerniente a la objetivación del currículo entendido como confluencia de prácticas. Su objetivo es debatir la posibilidad y la conveniencia de la inclusión de ítems que remiten a estas cuestiones en procedimientos y herramientas de autoevaluación de cursos por el cuerpo docente.

Palabras clave: enseñanza superior, currículos, profesores, evaluación.

\section{ABSTRACT}

This paper is an exercise in analyzing the current picture of Brazilian higher education and the conditions under which the educator's profession is carried out in most of the institutions. The text intertwines contexts, institutional objectives and conditions, and the curricular theory that permeates or might permeate assessment practices aimed at contributing to the professional development of higher education professors. The study focuses on the higher education institution's self-assessment curriculum when the course is considered as an analysis unit. It pays careful attention to issues listed by Gimeno Sacristán (2000) with regard to the objectivation of the curriculum understood as a confluence of practices. The goal is to discuss the possibility and convenience of including items that refer to these issues in procedures and instruments the faculty uses to undertake course self-assessment.

Keywords: higher education, curriculum, teachers, evaluation. 
Este trabalho procura realizar exercício de análise em que se entrelaçam contextos, objetivos e condiçóes institucionais, teoria curricular e prática avaliativa. Caracteriza-se como reflexão a respeito de ideias e princípios veiculados nas áreas de currículo e avaliação institucional, quando se toma o curso como unidade de análise. Tais ideias e princípios permeiam ou podem permear práticas avaliativas interessadas em contribuir para o desenvolvimento profissional ${ }^{1}$ de docentes que atuam em instituições de educação superior (IES) brasileiras.

No país, há que se considerar a oferta de educação superior com, pelo menos, quatro preocupaçóes: a heterogeneidade e diversificação do ofertado, em termos de tipos e dimensóes das instituiçóes e modalidades de cursos; o predomínio de instituiçóes e docentes do setor privado sobre o setor público ${ }^{2}$; as tentativas de regulação externa e a carência de tradição universitária, pois a primeira universidade brasileira data do início do século XX.

A discrepância entre os setores público e privado; o elevado número de instituiçóes desse setor, organizadas como faculdades isoladas ${ }^{3}$; e o número de funçóes docentes, classificadas no regime horista, remetem o olhar tanto para a formaçáo docente de seus profissionais como para os vínculos mantidos por eles com o ensino superior.

De outro lado, a pouca valorização do conhecimento pedagógico na formação do professor universitário, associada à fragilidade da pedagogia universitária como

\footnotetext{
${ }^{1}$ A expressão desenvolvimento profissional é utilizada por reforçar a ideia de professor como profissional do ensino e no sentido de formação contínua. De acordo com Marcelo (1999), o termo desenvolvimento conota evolução, continuidade, aperfeiçoamento, fortalecendo a ideia de que não há separação entre as fases inicial e contínua da formação. Um outro sentido do desenvolvimento profissional pressupóe abordagem de formação que valoriza o contexto, a organização e sua orientação para a mudança. Para Villegas-Reimers (2003), o desenvolvimento profissional dá-se como um processo de construção de cultura profissional em coerência com o contexto institucional.

${ }^{2} \mathrm{Na}$ Sinopse da Educação Superior de 2006, o Brasil conta com 2.270 IES, sendo 248 públicas e 2.022 privadas. Dessas, 1.583 são particulares e 439 comunitárias, confessionais ou filantrópicas. Esse mesmo levantamento revela que o total de funçóes docentes, no Brasil, é de 316.882, sendo 138.121 horistas, em classificação que comporta professores horistas, professores em tempo parcial e tempo integral. No setor público, constam 106.999 funçóes docentes (9.941 horistas), e no setor privado 209.883. Nas IES particulares há 118.739 (78.606 horistas), e nas comunitárias, confessionais ou filantrópicas 91.144 (49.574 horistas).

${ }^{3} \mathrm{Na}$ Sinopse da Educação Superior de 2006, consta que, das 2.270 IES brasileiras, 1.649 apresentam organizaçáo acadêmica de faculdades, escolas ou institutos. O setor privado concentra 1.567 delas, distribuídas em 1.268 particulares e 299 confessionais, comunitárias ou filantrópicas.
} 
campo epistemológico de existência recente, convergem para estabelecer um vácuo que favorece o impacto das políticas públicas na definição dos conhecimentos legítimos para o professor (Cunha, 2005). Na falta de outras referências, os conhecimentos expressos ou subjacentes a tais políticas adquirem o status de legítimos.

Com o intuito de contribuir para amenizar esse quadro, neste estudo exercitase o poder explicativo e orientador de aspectos da teoria curricular para a autoavaliação institucional e de cursos em perspectiva formativa (processual), participativa e formadora (voltada ao desenvolvimento profissional dos envolvidos no processo avaliativo). A escolha de temas relacionados a currículo deu-se em razão de seu potencial formativo reconhecido por Moreira (2002, 2005), ao final de seus trabalhos sobre o campo do currículo no Brasil e sobre o processo curricular do ensino superior.

Este texto insere-se em investigaçáo mais ampla a respeito da criação e da afirmação de espaços de formação ${ }^{4}$ (Cunha, 2005) na instituição de educação superior (IES), por meio da vivência de processos institucionais como o da autoavaliaçáo em perspectiva formativa e formadora. Admitem-se os riscos decorrentes do tipo de análise que transitará, de modo tangencial, por campos variados. O tema remete à dimensão operacional da autoavaliação institucional que se dá em cenário moldado pelo momento vivido pela educação superior em âmbito internacional, pelo quadro nacional e da própria IES.

Em escala mundial, é possível afirmar que a educação superior vive momentos de embate com o mundo do trabalho. Também há tensões quanto: à redefinição dos paradigmas epistemológicos sobre os quais se erigiu; à ampliação do controle externo sobre suas funçôes; à reorganização interna para atendimento a segmentos da sociedade que, até então, não alcançavam esse nível de ensino. Tais embates refletem-se no interior da instituição e incidem fortemente sobre decisōes curriculares.

4 "O impacto das políticas econômicas, internacionais e nacionais, sobre os sistemas educativos redundou na emergente discussão sobre o espaço da formação, tomando como referência para tal termo o enfoque sociogeográfico, que entende o espaço não apenas como unidade física, mas, também, e com mais importância, como uma definiçấo de poder. [...] O lugar de formação, antes visto como uma questáo de propriedade formativa, passou a exigir análises no âmbito das estratégias políticas, como afirmam Hargreaves e Fullan (2000), abordando as questôes relativas à geografia social da formação docente, reforçam a ideia de que o espaço em que se dá a formação docente passou a ser uma questáo importante, podendo modificar e acrescentar contingências às trajetórias gerais da formação, constituindo-se uma característica relevante das instituiçóes e interaçôes humanas" (Cunha, 2005, p.54-55). 
Antes de iniciar a discussão, pontuam-se algumas ideias subjacentes ao que se propóe realizar neste texto. Nele, a IES é concebida como lócus de formação profissional e cidadá, como produtora e socializadora de conhecimentos e vanguarda crítica da sociedade, ainda que náo desfrute do status oficial de universidade 5 . A mudança, certa instabilidade e insatisfação permanentes com o status quo constituem traços característicos da instituição concebida dessa forma.

A ideia de desenvolvimento profissional docente apoia-se em modelo de profissionalismo aberto (Perrenoud, 1993) que coloca o professor no centro do processo de melhoria da qualidade da educação e o torna responsável pela análise das necessidades institucionais, pelo debate e proposição de soluçóes e pelo autoaperfeiçoamento e avaliação dos resultados de suas intervençóes.

A participação do segmento docente no processo avaliativo reforça a condição de professor e contribui para a configuração da profissionalidade docente ao estimular a emergência de cultura profissional no seio da IES. A profissionalidade refere-se ao conjunto de atuaçôes, destrezas, conhecimentos e atitudes ligadas à prática que constituem o específico de ser professor (Gimeno Sacristán, 1991).

O processo avaliativo é considerado uma situação de trabalho docente, uma vez que não separa o profissional, sua prática e seus saberes. Os diferentes momentos do processo avaliativo de natureza participativa, com suas consultas e deliberaçóes, com o acesso a informaçôes organizadas sobre professores, cursos e IES, são concebidos como contribuiçóes à constituição de saberes profissionais (Tardif, 2006), como saberes trabalhados, incorporados no processo de trabalho docente e que só fazem sentido nas situações em que são construídos, modelados e usados.

A pergunta que orienta o exercício proposto é a seguinte: é adequado ou conveniente incluir itens relativos a currículo, entendido como confluência de práticas (Gimeno Sacristán, 2000) em procedimentos e instrumentos de autoavaliação de cursos que envolvem o corpo docente? Para respondê-la, faz-se breve referência à autoavaliação institucional e de curso; descrevem-se documentos oficiais que incidem sobre os currículos dos cursos de graduação; em seguida, analisa-se con-

${ }^{5}$ Lei n. 9.394, de 20 de dezembro de 1996. Estabelece as Diretrizes e Bases da Educação Nacional. Art. 52 - "As universidades são instituiçôes pluridisciplinares de formação dos quadros profissionais de nível superior, de pesquisa, de extensão e de domínio e cultivo do saber humano, que se caracterizam por: I - produção intelectual institucionalizada mediante o estudo sistemático dos temas e problemas mais relevantes, tanto do ponto de vista científico e cultural quanto regional e nacional; II - um terço do corpo docente, pelo menos, com titulação acadêmica de mestrado ou doutorado; III - um terço do corpo docente em regime de tempo integral." 
tribuição de questóes relativas a currículo para o desenvolvimento profissional docente; ao final, discutem-se limites e possibilidades da inclusão dessas questóes em processos autoavaliativos.

\section{A AUTOAVALIAÇÃO INSTITUCIONAL E A AVALIAÇÃO DE CURSOS DE GRADUAÇÃO}

A autoavaliação institucional ou avaliação interna pode ocorrer por iniciativa da IES, para atender a seus interesses; ser induzida por organismo externo, como estratégia de regulação ou controle; ou combinar iniciativa própria à política de avaliação externa. Desde 2004, o Sistema Nacional de Avaliação da Educação Superior (Sinaes) ${ }^{6}$ coloca a autoavaliação institucional ao lado da avaliação institucional externa como um dos seus três instrumentos. Os outros são a avaliação de cursos e o Exame Nacional de Desempenho do Estudante (Enade). A consideraçáo da autoavaliação institucional como um dos instrumentos do Sinaes pode contribuir para consolidar espaços de formação institucionais apoiados em práticas avaliativas.

$\mathrm{Na}$ perspectiva adotada nesta reflexão, a autoavaliação institucional dá-se como processo participativo, formativo e formador que procura: produzir uma visão de conjunto da IES; conhecer para compreender suas dificuldades e equívocos e potencializar as condiçóes de construir, com melhor qualidade, os agentes, a instituição e os contextos (Dias Sobrinho, 1996).

A avaliação institucional, inclusa a autoavaliação, é foco de interesse e conflitos sobre suas concepçôes e usos. $\mathrm{O}$ interesse pela avaliação institucional não se reduz a seu potencial de aperfeiçoamento ou de transformaçóes de natureza pedagógica e administrativa. Ele está relacionado também às exigências de regulação e controle por parte do Estado. A avaliaçáo institucional integra agenda internacional e ocupa lugar de destaque nas políticas oficiais, tanto institucionais quanto governamentais e de organismos internacionais financiadores da educação superior (Dias Sobrinho, 1998).

Este estudo prioriza a ideia de avaliação como oportunidade de autoconhecimento e de aperfeiçoamento, reconhece a contribuição desses processos à afirmação da identidade institucional, assim como a inviabilidade de cisão completa das duas facetas do processo - autorregulação e controle externo - com todos os conflitos que geram.

${ }^{6}$ O Sinaes foi instituído pela Lei n. 10. 861, de 14 de abril de 2004, tendo por objetivo assegurar o processo nacional de avaliação das IES, dos cursos de graduação e do desempenho acadêmico de seus estudantes (Brasil, 2007). 
A realização das finalidades e funções da IES concentra-se nos cursos que mantém. O curso é uma das menores unidades ou a menor unidade da estrutura organizacional de uma IES. Por sintetizar ou expressar essas finalidades e funçóes em um projeto específico de formação, é o segmento institucional mais examinado na avaliação.

Quando tratam de avaliação de cursos, Belloni e Belloni (2003, p.27-28) consideram três aspectos principais:

10) As condiçóes para o desenvolvimento do currículo: objetivos do curso; conteúdos curriculares; a perspectiva curricular adotada; a adequação dos conteúdos aos objetivos e ao perfil profissional pretendido; a proposta de organização curricular - disciplinas e atividades obrigatórias e optativas; funcionamento do curso - o fluxo de oferta de disciplinas, o desenvolvimento dos alunos; a qualidade do processo de ensino; a infraestrutura física, técnica e administrativa.

2o) Os processos desenvolvidos: as características do corpo docente; a operacionalização da proposta curricular e o fluxo de implementação das atividades e disciplinas; a avaliação da aprendizagem, a atuação e formação dos alunos; a contribuição dos estágios curriculares.

3o) Os resultados decorrentes das percepçóes de alunos e professores sobre o preparo para executar açóes e funçóes específicas do curso; preparo do concluinte, qualidade global do curso em relação a outras instituiçóes.

De modo similar, Franco (1997) lembra que em uma avaliação centrada no curso - nos objetivos, no currículo e em sua organização -, outros elementos são considerados: o corpo docente; o corpo discente; o corpo técnico-administrativo; a administração; o espaço físico, os equipamentos, a infraestrutura de apoio acadêmico e os recursos financeiros.

No âmbito do curso, é possível notar que, em grande medida, sua avaliação ocorre no currículo, compreendido como dispositivo que, definidas as finalidades e dadas as condiçóes, seleciona e organiza o que ensinar (conteúdos), para que (finalidades e objetivos) e para quem, seguindo-se do como e quando (metodologia de ensino e organização curricular).

Entre os procedimentos e instrumentos mais usuais em uma autoavaliação de curso, encontram-se os que incluem consulta aos públicos envolvidos como os surveys, grupos focais ou grupos de discussão e entrevistas. Os primeiros são os mais comuns. A elaboração coletiva dos instrumentos de consulta constitui etapa do 
processo autoavaliativo de natureza participativa e formadora. A participação pode ocorrer igualmente em outros momentos, como na análise e divulgaçáo dos dados e no processo decisório.

Outros procedimentos e instrumentos relativos a processos acadêmicos, como movimentação de estudantes, qualificação docente, pesquisa, extensão, processo seletivo e outros, comportam igualmente boa dose de participação. É nesse movimento de idas e vindas, embates, troca de informaçóes por dados organizados, que, se crê, ocorra o desenvolvimento profissional e a afirmaçáo de espaços formativos na IES.

Tal movimento evidencia o projeto (pedagógico) institucional como referência à dinâmica e ao sentido do processo avaliativo. É nesse movimento que se articulam ou se chocam a autorregulaçáo e o controle externo. É nesse movimento que, na autoavaliação de curso pelo corpo docente, o projeto institucional possibilitará a inclusão de temas ou itens relacionados a currículo que extrapolam os veiculados em documentos oficiais, ao favorecerem uma visão articulada de currículo e revelarem suas múltiplas inserçóes e implicações.

\section{DOCUMENTOS OFICIAIS COM INCIDÊNCIA SOBRE OS CURRÍCULOS DOS CURSOS}

A avaliação externa de cursos de graduação constitui um dos braços do controle governamental sobre as IES e seus cursos. Talvez o mais atuante. Os cursos, para serem autorizados, reconhecidos e reavaliados, recebem visitas de pares preparados pelo Ministério da Educaçáo (MEC). As visitas pautam-se por roteiros e orientação publicados, entre outros, no portal do MEC.

Essa modalidade de avaliação externa e o Enade atingem diretamente os cursos, e parte substancial do que neles é avaliado orienta-se pelas Diretrizes Curriculares Nacionais para os Cursos de Graduação (DCN). Em razão do acesso da IES a esses instrumentos que explicitam os padróes desejáveis em termos de estrutura, organização e funcionamento dos cursos, seus responsáveis e demais envolvidos com e pelas avaliaçóes externas dispóem de modelos confiáveis a seguir. Dessa forma, os instrumentos cumprem uma dupla função: regulam e oferecem concepção de curso e de qualidade passíveis de serem incorporadas como boas, desejáveis, adequadas e suficientes a quem pode desconhecer outras alternativas e carece de aprovação externa para funcionar, assim como de chancela oficial de qualidade para fins de publicidade. Por essas razóes, descreve-se brevemente cada um desses instrumentos, destacando o que trazem acerca de currículo. 
O Instrumento de Avaliação dos Cursos de Graduação 2006 contempla três grandes categorias: a) Organização didático-pedagógica; b) Corpo docente, discente e técnico-administrativo; c) Instalaçóes físicas. As questóes curriculares encontramse na categoria Organizaçáo didático-pedagógica, na parte que trata do Projeto Pedagógico do Curso (PPC). Nessa categoria, constam como indicadores do item currículo: coerência do currículo com os objetivos do curso, com o perfil desejado do egresso, com as DCN, e do corpo docente com a proposta curricular e também coerência dos recursos materiais específicos do curso com a proposta curricular. Constam ainda: estratégias de flexibilização curricular; dimensionamento da carga horária; adequação da metodologia de ensino à concepção de curso; inter-relação das unidades de estudo na concepçáo e execuçáo do currículo; dimensionamento da carga horária das unidades de estudo.

Junto com a avaliação dos cursos de graduação, o Enade consiste no segundo braço do Sinaes no que se refere à avaliação institucional externa. Ele objetiva aferir o rendimento dos alunos

em relação aos conteúdos programáticos previstos nas diretrizes curriculares do respectivo curso de graduação, suas habilidades para ajustamento às exigências decorrentes da evolução do conhecimento e suas competências para compreender temas exteriores ao âmbito específico de sua profissão, ligados à realidade brasileira e mundial e a outras áreas do conhecimento. (Brasil, 2005, p. 13)

As DCN reúnem um conjunto legal de orientaçóes para referenciar as IES quanto à organização de seus programas de formação e substituem o dispositivo legal que imperou na educação superior brasileira desde o final dos anos sessenta até o final do século XX: os currículos mínimos.

Os currículos mínimos consubstanciavam orientação curricular fundada em bases positivistas, com acentuada separação entre teoria e prática e pressupunham a completa preparação para o exercício profissional, sacramentada na concessão do diploma, que assegurava o exercício das prerrogativas e direitos da profissão. Definiam disciplinas e cargas horárias mínimas obrigatórias para cada curso. Os cursos diferenciavam-se quanto às disciplinas complementares e optativas.

${ }^{7} \mathrm{O}$ documento foi produzido por dois setores vinculados ao $\mathrm{MEC}$, atendendo aos padróes de qualidade definidos para a educação superior brasileira, às normas vigentes e às DCN para os cursos de graduação. 
As DCN para os Cursos de Graduação, implantadas com a vigência da nova Lei de Diretrizes e Bases (1996), diferenciam-se dos currículos mínimos por intencionar "servir de referência para as IES na organização de seus programas de formação" e permitir flexibilidade na construçáo dos currículos ao indicar áreas de conhecimento em vez de disciplinas com cargas horárias definidas ${ }^{8}$. Diferenciam-se por declarar "conferir maior autonomia às IES na definição dos currículos de seus cursos" e conceber a graduação como etapa de formação inicial?.

Como os currículos mínimos vigoraram por décadas, é possível afirmar que os atuais professores da educaçáo superior foram formados e/ou formadores sob a égide dessa orientação curricular. A força dos currículos mínimos ainda é visível nas propostas curriculares em desenvolvimento nas IES. Pesam fatores como: a tradição de três décadas, as mudanças nas bases epistemológicas sobre as quais os cursos se encontram apoiados e, em alguns casos, a interferência de associaçóes profissionais.

\section{QUESTÕES RELATIVAS A CURRÍCULO COMO CONFLUÊNCIA DE PRÁTICAS}

O desenvolvido até aqui indica que os tópicos sobre currículo que chegam à IES limitam-se ao constante nas DCN e nos roteiros de avaliaçáo externa, que acentuam o cuidado com a coerência entre meios-fins e os elementos curriculares. Relaçóes entre a IES, o curso, o mundo do trabalho e da ciência não são mencionadas, assim como entre a IES e o contexto local, regional, nacional, entre outras. No entanto, quando se trata de planejamento e gestão institucionais, tais relaçóes não podem ser ignoradas. Cunha e Leite (1996), em estudo que examinou a questão pedagógica na universidade, concluem que as decisóes pedagógicas na IES vinculam-se ao campo científico em que as profissóes estão inseridas, que esse campo é controlado de fora e desfruta, no seio da IES, prestígio proporcional ao usufruído pelo campo e/ou pela profissão correspondente na sociedade.

Dado o quadro apresentado, considera-se que a teoria curricular oferece elementos integradores fundamentais para que o professor perceba sua posição na IES, estabeleça relações necessárias à melhor compreensão de si como docente e constitua saberes profissionais assentados em bases mais consistentes. Desse cam-

${ }^{8}$ Edital n. 4/97, do Ministério da Educação/ Secretaria da Educação Superior (MEC/SESU). ${ }^{9}$ Diretrizes Curriculares Nacionais para os Cursos de Graduação, MEC/SESU. As diretrizes contemplam: o perfil do formando; competências/habilidades/atitudes; habilitaçôes e ênfases; conteúdos curriculares; organização do curso; estágios se atividades complementares; acompanhamento e avaliação (Parecer CNE/CES n.583/2001). 
po teórico, extenso, complexo e plurirreferenciado, o texto recorre às contribuiçóes de Gimeno Sacristán (2000), que apesar de não endereçadas à educação superior, oferecem amplo modelo explicativo de caráter genérico, considerado adequado aos propósitos das práticas avaliativas em foco (autoavaliação de curso superior, em perspectiva participativa, formativa e formadora, com e pelo corpo docente).

O autor apresenta o currículo como construção social e como um processo social com múltiplas expressóes, elemento essencial para que se possa compreender a prática pedagógica. Discute currículo, como confluência de práticas realizadas em instâncias diversas, práticas que são realidade em outros contextos e que vão lhe dando forma, antes de o currículo passar a ser realidade como experiência de aprendizagem para os alunos.

No processo de objetivação do currículo, tais práticas seriam realizadas em níveis ou fases distintas, mas interdependentes: o currículo prescrito, o apresentado aos professores, o currículo modelado pelos professores, o currículo em ação, o currículo realizado e o currículo avaliado ${ }^{10}$. Em resumo, o currículo pode ser entendido como "projeto seletivo de cultura, cultural, social, política e administrativamente condicionado, que preenche a atividade escolar e que se torna realidade dentro das condiçóes da escola tal como se acha configurada" (Gimeno Sacristán, 2000, p. 34).

Observa-se que essa noção de currículo refere-se a elementos não evidentes nos documentos mencionados até entáo. Entre eles, a ideia de seleçáo de cultura que implica escolhas e traz consigo a necessidade de clareza de objetivos, de assunção de responsabilidades, de que náo se pode abarcar tudo, ou, ainda, a de configuração dependente da instituição e de outras instâncias não exclusivamente legais ou oficiais. Tais ideias remetem ao projeto institucional, proclamam sua necessidade e importância.

É preciso lembrar que, para a base do sistema de educação superior, carente de aprovação oficial para atuar, pois a maioria das IES é privada e não universitária, a

${ }^{10}$ 1. Currículo prescrito - traz prescrições e/ou orientações que ordenam o sistema educacional no que se refere a currículo e que se constituem em pontos de partida para o controle do sistema. 2. Currículo apresentado aos professores - procede de diferentes âmbitos, sendo o mais influente o dos livros didáticos. 3. Currículo modelado pelos professores - revela-se nos planos elaborados por eles ao traduzirem as orientações ou prescriçôes recebidas de uma ou mais fontes. 4. Currículo em ação é a prática que se apresenta no cotidiano, nas tarefas acadêmicas. 5. Currículo realizado refere-se aos efeitos produzidos pela prática que atingem alunos e professores. 6. Currículo avaliado - ressalta certos componentes, conteúdos, acaba impondo critérios para o ensino e para a aprendizagem dos alunos (Cf. Gimeno Sacristán, 2000, p. 104-106). 
orientação oficial externa chega com força de lei. Com isso, neutraliza-se a potencial abertura para questionamentos ligados à seleção (Quem? Quando? Como? Onde? Para quê? Para quem?) e ao reconhecimento da configuração curricular condicionada cultural, social e administrativamente. A introdução de questôes dessa natureza ao público visado indica-lhe que a relação MEC-IES não se dá linearmente e sim condicionada a fatores diversos, sendo a instituição parte implicada nesse processo, não apenas um espaço executor.

A orientação curricular oficial e as orientaçôes das avaliaçôes externas incidem sobre as práticas curriculares de modo que se enquadrem em modelo explicativo próprio a estruturas de gestáo centralizadas. Gimeno Sacristán (2000) argumenta que ao propor um modelo de interpretação do currículo como algo construído no cruzamento de influências e campos de atividade diferenciados identificou um modelo explicativo em que os espaços de autonomia são limitados a priori, tal como indicado nos documentos e procedimentos oficiais.

O modelo serve para mostrar as disfunçóes e esferas de autonomia que representam forças concorrentes. Ao deixar claras as restriçóes, o modelo revela espaços ou brechas a serem ocupados pelas IES e seus professores. Esclarece formados e formadores sob a égide dos currículos mínimos o movimento realizado até a materialização do currículo junto ao aluno e seus efeitos sobre os envolvidos. Situa e coloca o corpo docente como sujeito, com parcela de responsabilidade sobre o decidido e como parte afetada pelo realizado. Nas práticas avaliativas relacionadas a currículo, não são usuais itens que mencionem o processo de construção curricular em instâncias diversas, o embate de interesses e a distribuição de responsabilidades no decorrer do processo.

Inspirados nas ideias expostas, os itens seguintes poderiam integrar discussões preliminares a respeito da autoavaliação de cursos, assim como poderiam constar de um roteiro para construção de um formulário, de um questionário, uma entrevista ou um grupo focal. As questóes enunciadas não seguem uma ordem, ou critério pré-definido, nem pretendem ser exaustivas. Apenas ilustram o que poderia ser incluído.

Quanto à noção de currículo, como projeto seletivo de cultura que preenche a atividade escolar, cabem as seguintes questôes: Quem são os responsáveis, na IES e no curso, pelo processo de construção do currículo e do PPC? Qual o lugar do corpo docente do curso nesse processo? Quem define carga horária, disciplinas e atividades a incluir ou excluir e o formato do currículo? Que atores têm ciência do referencial utilizado para realizar a seleção em questóes curriculares? Quem partici- 
pa da definição do currículo do curso? Como se dá o reconhecimento da influência de outros setores ligados ao curso, situados fora da IES?

Com relação ao currículo prescrito é possível indagar a respeito do conhecimento das DCN, conhecimento das regras e orientaçôes institucionais sobre alteraçóes curriculares. Quanto ao currículo modelado pelos professores cabem questóes sobre a participação e responsabilidade docente em relação à elaboração de planos de ensino, definição de ementas, definição de componentes curriculares, ao reconhecimento e posicionamento do corpo docente e de cada professor acerca dos embates em torno do conhecimento válido em cada área e dos perfis profissionais definidos na IES e fora dela. Com relação ao currículo em ação cabem questóes que ampliem o entendimento do professor a respeito da variedade de situaçóes acadêmicas que se caracterizam como curriculares, ao comportarem encontros entre professores e alunos mediados pelo conteúdo no âmbito de um projeto de formação: aulas, iniciação científica, estágios, trabalhos de conclusão de curso, visitas técnicas e outras. Quanto ao currículo realizado, questionar a respeito do impacto do vivido no curso sobre os estudantes e os próprios professores, tendo como pano de fundo o projeto de formação. A respeito do currículo avaliado, situar avaliação da aprendizagem pelo docente ou curso e avaliação de desempenho do aluno pelo MEC/Sinaes/Enade, destacando a força dos critérios definidos para avaliação em geral sobre o currículo moldado pelos professores, o currículo em ação e o currículo realizado.

$\mathrm{O}$ rol de itens a serem discutidos e/ou incluídos assemelha-se a um programa de formação e guarda tais características em razão da perspectiva de autoavaliação adotada. A inclusão de questóes ou itens de discussão na autoavaliação de curso não exclui as demais. $\mathrm{O}$ projeto institucional funciona como o grande crivo nessa seleção.

\section{CONSIDERAÇÕES}

O objetivo deste texto consistiu em realizar um exercício analítico, cotejando autoavaliação de curso em perspectiva formativa e formadora com elementos de teoria curricular, com vistas a introduzir no processo avaliativo alguns desses elementos, argumentando-se a favor de seu potencial formador.

Procurou-se evidenciar esse traço nos elementos escolhidos, indicando que explicitar o processo de construção curricular permite ao professor compreender o que se lhe apresenta, situar o jogo de forças subjacente à ideia de currículo, conhecer seu espaço de ação, sua responsabilidade no que cria, transforma e reproduz. Por outro lado, a explicitaçáo favorece o entendimento de que a construção do currículo 
começa muito além da IES em nichos, instâncias diversas que disputam espaço e colaboram entre si para tornar o currículo realizado na IES algo adequado e coerente aos estudantes e às finalidades que persegue. De posse desses elementos - para o especialista, simples fragmentos ou pouco mais - acredita-se que o professor reúna melhores condiçóes para desenvolver sua profissionalidade, uma vez que coexistem na mesma pessoa, o profissional, o pesquisador e o professor da educação superior.

$\mathrm{O}$ modo como os itens aqui selecionados integrarão procedimentos e instrumentos de avaliação depende de condicionantes internos. Vincula-se às peculiaridades de cada IES, às políticas institucionais em vigor, à cultura institucional e ao seu projeto de avaliação.

Os elementos da teoria curricular selecionados para integrar a autoavaliaçáo do curso passam por transformação antes de serem apresentados aos professores. É preciso redigi-los e organizá-los de modo que possam ser entendidos, de modo a fazer sentido para o público a que se destina. Vale-se de algo produzido, com outro propósito, em outra instância, para transformá-lo em algo compreensível e esclarecedor para os destinatários. Subjaz a esse processo um projeto formador que envolve a ampliação do conhecimento acerca de um objeto: o currículo.

É preciso lembrar que a escolha de quais aspectos, dimensóes ou processos relacionados ao objeto seráo avaliados, costuma ser suficiente para que se considere o estabelecido como desejável, ou seja, como critério norteador e, por conseguinte, regulador do que se avalia. Daí a possibilidade de a autoavaliação apresentar-se simultaneamente regulatória e emancipatória.

Como se trata de recorrer à autoavaliação de curso para introduzir elementos informativos e críticos acerca de questôes curriculares, é possível que aconteça imposição de problemática, ao colocar o professor diante de questionamentos que não são seus, embora deles possa ter ciência por outras vias. Tal fato pode ser minimizado com a adaptação cogitada e adequação às condiçôes institucionais.

O esforço analítico e os riscos enfrentados decorrem do interesse em fortalecer alternativas institucionais que concorram para o desenvolvimento profissional de professores da educação superior. Investe-se em perspectiva que lhes permita compreender as imbricaçôes e implicaçôes de suas decisões e de seus pares, para além das políticas oficiais, de si mesmos, de suas disciplinas e pesquisas. A autoavaliação é uma alternativa para tanto. Ela exercita o autoconhecimento. É recurso para a afirmação de espaços de formação na IES. Os cenários nacional e internacional da educação superior não deixam alternativa senão ocupá-los. Portanto, é preciso fazer mais com muito menos. 


\section{REFERÊNCIAS BIBLIOGRÁFICAS}

BELLONI, Isaura; BELLONI José A. Questões propostas para uma avaliação institucional formativa. In: FREITAS, Luiz Carlos de (Org.). Avaliação de escolas e universidades. Campinas: Komedi, 2003.

BRASIL. Ministério da Educação. Secretaria de Educação Superior. Diretrizes Curriculares Nacionais para os cursos de graduação. Disponível em: <http://portal.mec.gov.br/ sesu/index.php?option $=$ content $\&$ task $=v i$ ew\&id=430\&ltemid=420>. Acesso em: 22 jun. 2008.

Edital n. 4/1997. Disponível em:

<http://portal.mec.gov.br/sesu/arquivos/ pdf/e04.pdf $>$. Acesso em: 22 abr. 2008. - Instrumento de avaliação dos cursos de graduação. Brasília: Inep, 2006. - Resumo técnico: Enade 2004. Brasília: Inep, 2005.

. Sinopses Estatísticas da Educação Superior Graduação 2006. Disponível em: <http://www.inep.gov.br/superior/ censosuperior/sinopse/>. Acesso em: 14 jul. 2008.

Sistema Nacional de Avaliação da Educação Superior: da concepção à regulamentação. 4. ed. Brasília: Inep, 2007.

CUNHA, Maria Isabel da. Aportes teóricos e reflexões da prática: a emergente reconfiguração dos currículos universitários. In: MASETTO, Marcos (Org.). Docência na universidade. Campinas: Papirus, 1998.

- Impactos das políticas de avaliação externa na configuração da docência. In: CUNHA, Maria Isabel da (Org.). Formatos avaliativos e concepção de docência. Campinas: Autores Associados, 2005.

CUNHA, Maria Isabel da; LEITE, Denise B. C. Decisões pedagógicas e estruturas de poder na universidade. Campinas: Papirus, 1996.

CUNHA, Maria Isabel da et al. As Políticas públicas de avaliação e docência na universidade. In: CUNHA, Maria Isabel da (Org.). Formatos avaliativos e concepção de docência. Campinas: Autores Associados, 2005.
DIAS SOBRINHO, José. Avaliação institucional: marco teórico e campo político. Avaliação: Revista de Avaliação Institucional das Instituições de Ensino Superior, v. 1, n. 1, p. 15- 24, jul.1996.

Avaliação institucional da educação superior: fontes externas e internas. Revista da Rede de Avaliação Institucional da Educação Superior, v. 3, n. 4, 1998.

FRANCO, Maria Laura P. Barbosa; METS, Lisa A. Avaliação de currículos e de programas. Brasília: Universidade de Brasília, 1997.

GIMENO SACRISTÁN, J. Consciência e ação sobre a prática como libertação profissional dos professores. In: NÓVOA, Antonio. Profissão professor. Porto: Editora Porto, 1991.

. O Currículo: uma reflexão sobre

a prática. 3. ed. Porto Alegre: ArtMed, 2000. HARGREAVES, Andy; FULLAN, Michael. A Escola como organização aprendente: buscando uma educação de qualidade. 2 . ed. Porto Alegre: ArtMed, 2000.

MARCELO, Carlos. Formação de professores para uma mudança educativa. Porto: Editora Porto,1999.

MOREIRA, Antonio Flávio Barbosa. O Campo do currículo no Brasil: construção no contexto da ANPEd. Cadernos de Pesquisa, n. 117, 2002.

. O Processo curricular no ensino superior no contexto atual. In: VEIGA, IIma Passos Alencatro; NAVES, Marisa Lomônaco de Paula (Org.). Currículo e avaliação na educação superior. Araraquara: Junqueira \& Marin, 2005.

PERRENOUD, Philippe. Práticas pedagógicas, profissão docente e formação. Lisboa: Dom Quixote; Instituto de Inovação Educacional, 1993.

SILVA, Tomaz Tadeu da. Documentos de identidade: uma introdução às teorias do currículo. Belo Horizonte: Autêntica, 1999. TARDIF, Maurice. Saberes docentes e formação 
profissional. 6. ed. Petrópolis: Vozes, 2006. VILLEGAS-REIMERS, Eleonora. Teacher professional development: an international review of the literature. Paris: Unesco; International Institute for Educational Planning, 2003.

Recebido em: novembro 2008

Aprovado para publicação em: maio 2009 